\title{
Experiences of Intersecting Inequalities for Poor Hindu Women in Pakistan
}

Through first-hand accounts of marginalisation and discrimination, the research paper in question explores the reality of life in Pakistan for poor Hindu women and girls who face intersecting and overlapping inequalities due to their religious identity, their gender and their caste. They carry a heavy burden among the marginalised groups in Pakistan, facing violence, discrimination and exclusion, lack of access to education, transportation and health care, along with occupational discrimination and a high threat of abduction, forced conversion and forced marriage.

\section{Key messages}

- There are over 8 million Hindus in Pakistan (approximately 4 per cent of the total population), according to the Pakistan Hindu Council.

- Most are from poor and marginalised Scheduled Caste communities, with the majority of marginalised Hindus living in rural Sindh.

- Discrimination based on religious identity intersects with many of the other issues, for example Hindu women's ability to travel and move around their locality (because they are harassed on public transport).

- Access to healthcare, and education, including the learning materials used within schools and colleges, and the ability to celebrate Hindu festivals were all other examples of areas of life limited by religious discrimination and exclusion.

- The very real threat of abduction and forced conversion (to Islam) for Hindu girls and young women has resulted in the men and elders in their community placing extensive restrictions on their mobility; keeping them trapped in low income jobs such as sanitary or housekeeping work.

\section{Context}

Pakistan's Constitution promises fundamental rights, correspondence of equal opportunity, law, social, economic and political justice, and freedom of thought, expression, belief, faith, worship and association, subject to the law and public morality to its citizens. However, Pakistan's religious minority communities (including Hindus), which, according to the last 1998 Census constitute less than 4 per cent of the total population, often face significant discrimination, subject to

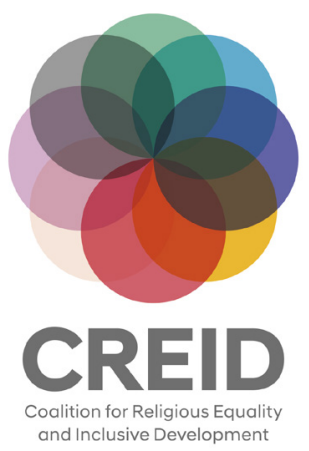


issues such as violence, forced conversions and attacks on worship places. As well as experiencing poverty and misery differently from men of the same class, women from religious minorities also face violence, discrimination and exclusion, lack of access to education, transportation, and health care, along with occupational discrimination and a high threat of abduction, forced conversion, and forced marriage.

Ninety per cent of Pakistan's Hindu population is poor and marginalized, living across communities of approximately 40 different 'Scheduled [lower] Castes'. The majority of marginalised Hindus live in rural Sindh, where girls and women in households bear a disproportionate share of the work of, and responsibility for, feeding and caring for family members through unpaid household work, alongside collecting firewood, water, and fodder, and caring for the livestock. Women living in urban areas of Karachi city are almost always engaged in working indoors, alongside outside jobs like being domestic workers (housekeeping), labourers, sanitary workers, sweepers, and selling dried fruits and bangles. Hindu women with an education are rarely allowed to work as a teacher, never mind other professional roles.

"Ninety per cent of Pakistan's Hindu population is poor and marginalised"

\section{Methodology Note}

This research was carried out from March-June 2020 in Karachi, the largest city in Pakistan, which has an estimated Hindu population of 250,000 . It explored poor Hindu women's marginalisation through three key axes.

1. How and where they experience discrimination based on their religious identity.

2. How and where they experience gender discrimination (including within their own communities).

3. How their experiences of discrimination are different from the experiences of the poor men in their communities.

Four focus group discussions (FGDs) were conducted with 46 participants; 34 women and girls (across three focus groups) and 12 men. All belonged to the Scheduled Caste communities, representing the most economically marginalised of the Hindu population in Pakistan. FGDs used a participatory ranking methodology called Pile, Rank and Analyse (PRA). This technique enables participants themselves to identify problems and challenges, and rank these in order of their priority. The researcher then facilitated discussions within each FGD to unpack each threat and identify cross-cutting themes that impact the lives of women and girls in myriad ways. These discussions were recorded, enabling the research to draw on a rich data, emphasising the voices of the participants and highlighting their lived experiences.

The ranking process and focus groups were led by a researcher who is herself a Hindu woman living in Pakistan and who has experienced similar discrimination and exclusion. This enabled her to connect well with the participants and explain the research questions in a way that she knew they would understand. She was also able to put them at ease by sharing examples of her own marginalisation as a Hindu woman in Pakistan. 


\section{Key findings}

In order of severity, starting from the most severe and widespread, the top seven threats identified as facing poor Hindu women and girls were:

1. Discrimination based on religious identity, particularly as a result of their dress and appearance when out in public;

2. Sexual harassment and bullying;

3. Fear of abduction;

4. Fear of forced conversions and forced marriages;

5. Gender discrimination, within both their own communities and wider society, particularly domestic violence and punishment if they try to speak out against the violence they face within wider society;

\section{Lack of access to education;}

\section{Restricted dress and mobility.}

Discrimination based on religious identity was recognised as intersecting with many of the other issues that arose in the discussions. For example, Hindu women's ability to travel and move around their locality is heavily affected by religious discrimination and harassment, along with their ability to rent houses to live in or shops from which to sell the wares typical of their caste. When people learn that a woman is Hindu, typically from her traditional dress, the harassment ranges from insults and staring, the refusal to sit close to the woman on public transport, or even inappropriate touching, to a simple refusal to continue a transaction with her, such as the renting of a property. Access to healthcare, and education, including the learning materials used within schools and colleges, and the ability to celebrate Hindu festivals were all other examples of areas of life limited by religious discrimination and exclusion. Despite this extensive discrimination, experienced on a daily basis, Hindu women and girls did not want to abandon their religion, a fact that stands in contrast to the perception of a growing number of cases of Hindu families being forced to convert to Islam due to debilitating poverty exacerbated by Covid-19.

Sexual harassment and bullying from wider society were identified as being particularly prevalent on public transport, which, due to their economic exclusion, these Hindu women are limited to using in order to be mobile. Domestic violence was identified as a problem within the Hindu community, however it was acknowledged that no-one really speaks about this violence and the women expressed a desire not to say anything detrimental about the men in their community for fear of adding to the negative portrayal of their community by wider society. Similarly, Hindu men are reluctant to challenge the violence the women and girls in their community experience at the hands of men within wider society, as they don't want to invite further exclusion and harassment. Instead, the women stated that they direct their anger and frustration at them which leads to them silencing themselves in the future when they experience violence and harassment.
"Hindu women's ability to travel and move around their locality is heavily affected by religious discrimination and harassment" 
Key discussion points that were repeated throughout the FGDs included the impact of Hindu women wearing traditional Hindu dress in public, something which made them identifiable as non-Muslim which often leads to discrimination and harassment; the very real threat of Hindu girls and young women being abducted and forced to convert to Islam, which was recognised by participants as being the reason community men and elders place extensive restrictions on Hindu women and girls' mobility; and the limits on Hindu women and girls' job opportunities as a result of their religious identity intersecting with their caste, restricting them to working as sanitation workers and house maids.

\section{Policy recommendations}

Based on the experiences shared by participants in all four FGDs, the following recommendations are made to tackle the marginalisation and discrimination faced by poor Hindu women and girls in Pakistan:

- The Criminal Law (Protection of Minorities) Bill that was first proposed to provincial Sindh government in 2016, and later as an amended version with the objected clauses removed in 2019, must be passed in order to protect Hindu girls under the age of 18 from forced marriage and forced conversion. This Bill must uphold the recommended five years in prison and give lakh $(500,000)$ rupees penalty of punishment for those who groom, abduct and forcibly convert Hindu girls and young women.

- All textbooks and curriculum resources from primary school to college must be modified to ensure the removal of hate speech and discriminatory attitudes towards Hindus, especially where this is related to the history of the partition of India. Additionally, there must be effective mechanisms of complaint in place to allow Hindu students in educational institutions who experience discrimination on the basis of their religion to report this discrimination and for action to be taken.

- Religious minority women should be integrated into mainstream politics. Specifically, there must be seats within the existing quotas reserved for minority women in local, provincial and national assemblies in order to encourage their political participation and to ensure representation in decision-making. They must be included in programmes for their socioeconomic empowerment at governmental and non-governmental levels.

- Data must be recorded on acts of violence against minorities, and Hindu women in Sindh specifically, including forced conversion, abductions, and harassment in both rural and urban areas. This will form a clearer picture of the reality of the violence and harassment Hindu women face and better equip non-governmental organisations and the Hindu community to advocate for the legislation needed for their protection.

- Job quotas for minorities must be implemented correctly, with jobs other than sanitary work and sweeping made accessible to minority women. 
- Independent commissions for religious and gender equality, or similar institutions, should be set up to receive and investigate complaints related to minority women. They should also offer advice to victims of discrimination and undertake awareness-raising activities to promote the principles of non-discrimination and promote understanding between different communities.

\section{Further reading}

Maheshwary, S. (2020) 'Poor Marginalised Hindu Women in Pakistan' in M. Tadros (ed.) Violence and Discrimination against Women of Religious Minority Backgrounds in Pakistan, CREID Intersection Series: Gender and Religious Inequalities, Brighton: Institute of Development Studies, DOI: 10.19088/CREID.2020.003

Rana, M. (2020), 'Teenage Hindu Girl Committed Suicide after being Gang-Raped Twice', Ravadar, 23 October

Ravadar (2020), 'Plight of Hindu Women Vendors of Empress Market', Ravadar, 14 September

Tadros, M. (ed.) (2020) Violence and Discrimination against Women of Religious Minority Backgrounds in Pakistan, CREID Intersection Series: Gender and Religious Inequalities, Brighton: Institute of Development Studies, DOI: 10.19088/CREID.2020.003

\section{Credits}

This policy brief draws on the CREID paper 'Poor Marginalised Hindu Women in Pakistan' by Seema Maheshwary. It was compiled by Amy Quinn-Graham and edited by Emilie Wilson. It was produced as part of the Coalition for Religious Equality and Inclusive Development (CREID), a consortium funded by UK Aid from the UK government which provides research evidence and delivers practical programmes which aim to redress the impact of discrimination on the grounds of religion or belief, tackle poverty and exclusion, and promote people's wellbeing and empowerment.

The opinions expressed are those of the author and do not necessarily reflect the views or policies of IDS or the UK government

CREID Policy Briefings are published by the Institute of Development Studies and aim to share key research findings and make practical recommendations for policymakers and donors.

(cc) BY This is an Open Access publication distributed under the terms of the Creative Commons Attribution 4.0 International licence (CC BY), which permits unrestricted use, distribution, and reproduction in any medium, provided the original authors and source are credited and any modifications or adaptations are indicated.

\section{DOI: 10.19088/CREID.2020.012}

\section{Institute of Development Studies, Brighton BN1 9RE, UK \\ $\mathrm{T}+44(0) 1273606261$ \\ $\mathrm{F}+44(0) 1273621202$ \\ E creid@ids.ac.uk \\ Wwww.ids.ac.uk/creid \\ T@CREID_Dev}

CREID partners

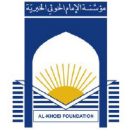

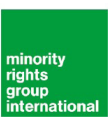

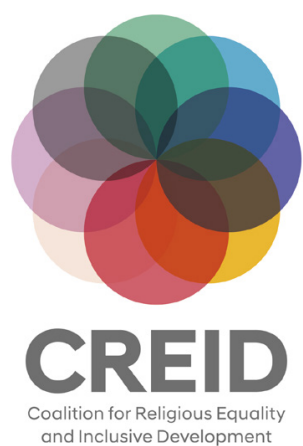

